\title{
Development and implementation of an algorithm for preventive machine maintenance
}

\author{
Mario Di Nardo $^{a^{*}}$, Giuseppe Converso ${ }^{a}$, Francesco Castagna ${ }^{\mathrm{b}}$ and Teresa Murino $^{\mathrm{a}}$
}

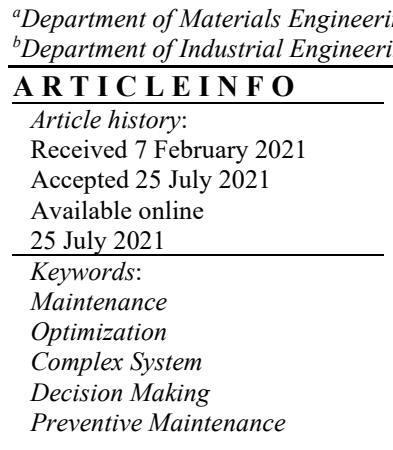

${ }^{a}$ Department of Materials Engineering and Operations Management, University of Naples Federico II, Italy ${ }^{b}$ Department of Industrial Engineering, University of Naples Federico II, Italy

\section{A B S T R A C T}

This paper aims to develop a maintenance optimization model to maintain a high level of efficiency and reliability of the machinery. The methodological approach is based on preventive maintenance through the partial or total replacement of critical components. Although an intermediate intervention control, the focus is on a particular machine that has stopped several times, reducing its operational availability and resulting in a high cost of non-production. This study uses a Weibull model to analyze and optimize the correct maintenance process of the machinery considered. The failure data are then analyzed and scheduled. The final purpose is to standardize the operators' intervention procedures to reduce the time for the same interventions.

\section{Introduction}

(C) 2021 Growing Science Ltd. All rights reserved.

The topic of maintenance is widely covered in the scientific literature. It includes many different areas, and it may be considered in several aspects. In the years, maintenance has focused on the activities' optimizations. It is essential to put into evidence the most critical items considered in the maintenance activities. Maintenance is a critical activity in the industrial sector, where the productivity of workers depends above all on proper management (Geisler, 2002). It still is considered operating costs, mainly due to the high intensity of their facilities (Ciarapica et al., 2008) and limits the productivity of an organization (Carnero et al., 2016). Moreover, maintenance activities are an essential source of knowledge management (Cárcel-Carrasco et al., 2020). We propose the categorization that we found in Lidén $(2015,2016)$, where three classes of tactical maintenance scheduling problems are the following: (1) deterioration-based maintenance scheduling, (2) maintenance vehicle routing, and team scheduling, and (3) possession schedule. Maintenance plays a central role in ensuring continuous production and improving equipment utilization. To achieve these aims, leasing or sharing complex equipment by multiple users combined with a promising way (Exner et al., 2017). The advantages of PSS-based maintenance service were evaluated by Marchi et al., (2016) and these allow being competitive and supporting sustainability and decreasing energy consumption in the steel industry. The business maintenance function must ensure the continuity and smooth functioning of production activities; it is transformed into scheduled work, characterized by rationality and skills to offer the company more

\footnotetext{
* Corresponding author.

E-mail addresses: mario.dinardo@unina.it (M. Di. Nardo) 
complete and economical solutions and preserve and improve the devices to guarantee the safety health of the worker (Irhirane et al., 2019). The maintenance optimisation activities go through the affirmation of a real Maintenance Engineering, which becomes preventive and predictive, where there are unavoidable costs and wise investments of company resources to ensure the plants' continuity (Zequeira and Bérenguer, 2005). Before carrying out any intervention to improve the maintenance management service, it is necessary to initially make a data collection campaign to highlight the problems, with a description of the intervention's problem and description. To solve the maintenance problem, the machine's operational availability will be improved, or the number of failures preventing costly failures has reduced. However, it is impossible to use the optimizations' model policies of total and partial substitution present in the literature, mainly for three reasons: the first reason concerns cyclical preventive maintenance. The second reason relates to the time taken to carry out preventive maintenance. Finally, the third reason concerns the definition of the maintenance cycle of the machine. It will be shown that the total maintenance cost decreases even if the number of intermediate checks increases. In order to get this result, it was developed and proposed an ad hoc mathematical model: continuous improvement of the machine's operational availability and containment of overall maintenance costs, implemented by the theory of reliability.

This study develops an algorithm that optimizes maintenance policies with revision of batch end, so in the next sections will be analyzed in detail only jobs that deal with optimization models and algorithms through simulation. The remainder of this paper is organized as follows. The second Section reviews the most relevant studies from the literature. The model formulation and the solution approach are presented in Section 3. Section 4 presents the results of a numerical study, Section 5 presents the model's implementation, and Section 6 draws a final results sensitivity analysis from the simulations conducted. Finally, the work concludes with suggestions and future research directions.

\section{Main models and optimization methods}

The literature review on optimizing maintenance activities has shown various models and methods for determining the most appropriate maintenance strategy depending on the context examined. The study revealed a strong dependence between various implementations and the productive environment, from time to time examined. This problem depends on many elements, which are constraints of the optimization process. The first is the weight to be given to critical variables, such as safety, reliability cost, availability, etc.

In order to solve the maintenance problem, it should be highlighted that can not be used optimization models of preventive policies for three reasons:

1) In the literature, the preventive maintenance model's policy adopted for the substitution patterns total is referred to as the standard policy of preventive maintenance. This is characterized by operations carried out periodically, which involve the total replacement of a specific machine or component that has not yet failed with a new one. To prevent uncontrolled collapse, a particular type of preventive maintenance, called revision maintenance, is adopted. It is based on complete inspection and repair, carried out periodically, by disassembling and inspecting-controlling the whole plant/machine in order to repair or change only the damaged parts or worn.

2) In the literature, the models allow determining the instant of time that allows minimizing the total cost of maintenance. Instead, the customer, who requires central control of every $10 \mathrm{~km}$ of cable wrapped in order to obtain an increased assurance on the quality of the product, shall impose preventive maintenance operations.

3) The maintenance cycle, i.e., that cycle that starts and ends with the machine in condition "as good as new," i.e., with a new machine, with the reliability of $100 \%$, is defined in function of optimum time at which to carry out the replacement; in this case, the maintenance cycle coincides with the production batch, i.e., begins and ends with the sizes to be produced, therefore, is different from size to size. 
We note that maintenance management is part of asset management, defined as: "coordinated activity of an organization to realize value from assets." Asset management concerns the whole life cycle of assets, whereas maintenance management is mainly relevant during the assets' operational phase. By improving maintenance decisions during this phase, maintenance management can increase the value realized by assets. Firstly then, an agent is a stakeholder in the modeling process. The agent may be the decision-maker, modeler, operator, or system owner. Next, on assets, a system is an asset that performs an operational function. It is subject to deterioration and, therefore, also to maintenance interventions. A system has a hierarchical structure: a system may be viewed as comprising sub-systems, with each subsystem comprising sub-systems, and so on, depending on the level of resolution. A unit or component is part of a system that is subject to maintenance interventions and cannot be further subdivided into subunits that are individually subject to any maintenance intervention. On maintenance actions, we distinguish preventive and corrective maintenance actions. A preventive maintenance action is performed before a unit's failure, a corrective maintenance action after failure. Preventive maintenance actions should be planned or triggered, for instance, based on time, age, usage, or condition information. The terms prognostic, predictive, and condition-based are merely jargon associated with planned preventive maintenance based on condition information. Finally, we note that various optimality criteria are considered when specifying maintenance policies. Examples are minimization of the long-run cost rate, minimization of the total (discounted) costs during a finite time horizon, maximization of the long-run availability, and maximization of the reliability during subsequent missions (de Jonge \& Scarf, 2020). Industrial plants are complex systems that can simplify problems by considering a system as a set of few components (Jardine \& Tsang, 2013). This implies that the results are poorly applicable to concrete cases, governed by high complexity. Essentially this approach is to identify, inside the system to be optimized, a few simple components and to model the behaviour probabilistically (Vineyard et al., 2000). For the whole optimization process, the consequences will be evaluated, in terms of risk, interruption of production, and cost of different fault types, which may incur the various components considered. The modern production systems are complex, consisting of many components, tightly interconnected, from a functional standpoint.

Many components can be defined as Critical (C. C.); they play a fundamental role due to their importance in the production system. The manufacturer has designated these as requiring unique fabrication, maintenance, inspection, or operation. The range of failures/accidents that can occur is extensive, and it can be predicted, molded, and countered through complex models and simulations. It is necessary to develop a maintenance policy optimal in terms of critical parameters - such as safety - but also feasible in terms of reliability and economic sustainability. Therefore, the model representation of the system must contain a variable that somehow represents the maintenance plan adopted and, according to this, returns a value that is univocally associated with a certain amount of risk. In this way, it is possible, set the amount of risk considered acceptable to find a suitable maintenance plan (Chemweno et al., 2015). For example, concerning safety (parameter increasingly considered by researchers, especially in more recent works), there are different ways to evaluate the amount of risk numerically. In particular Vaurio (1995), states that "optimization in terms of risks is equivalent to the minimization of the average time of unavailability". Hence, the optimization process focuses on expressing the representative variable time of the maintenance plan adopted. This methodology optimizes the maintenance, pursuing goals simultaneously in terms of safety and availability (Zhang et al., 2020). The variable representative of the maintenance plan adopted identified with the single interval time, which elapses between two successive maintenance operations. In this way, it is possible to find a maintenance plan that ensures proper security levels and does not involve excessively frequent production interruptions to permit checks and maintenance operations. It is noted that the structure of the function that links the average time of unavailability (unavailability time divided by total time) with the frequency $\mathrm{T}$ of maintenance operations, and the values assumed by the various parameters contained in it, depends on the maintenance policy to be adopted. For example, preventive and proactive maintenance ensures equal frequency of operations, more excellent safety and reliability, and only incidental and corrective maintenance, but higher costs linked to operations. However, the problem of costs remains unresolved. In other words, it is a function 
in which the cost is always expressed as a function of the time interval $\mathrm{T}$, which elapses between two successive maintenance operations. This function is minimized at a value of $\mathrm{T}$ either too significant (it would have an increase in the costs related to the consequences of faults) or too small (in this case, the costs would increase for the maintenance and loss of productivity caused by constant interruptions). In the first case, there would be an increase in costs related to the consequences of failures frequently made by the infrequency of maintenance. The second case would occur instead of an increase in maintenance costs, which sharply reduced plant productivity and, unavoidably, sales. Numerous studies in this field (Furlanetto et al., 2007) showed that regardless of the productive environment from time to time, the optimal timing $\mathrm{T}$ of maintenance intervals optimized based on the cost tends to be higher than optimized based on safety. The two optimal do not coincide; it is necessary to find an intermediate solution that takes both. The solution that protects more workers' safety suggests the determination of the time T, and it is necessary to start with a minimum level of safety considered acceptable and the costs associated with it. Suppose the business budget is not enough to support these costs. In that case, it is indispensable to reconsider the maintenance strategy to return satisfactory and compatible solutions in terms of economy and safety (for example, trying to replace a corrective with proactive maintenance and so on). Vaurio (1995) discusses the existing link between maintenance and probability/frequency where faults and other unfavorable events occur.

\section{Optimization model for maintenance policies for the final batch}

Consider a manufacturing flow shop system that produces customized orders. Although an intermediate intervention control, the focus is on a particular machine that has stopped several times, reducing its operational availability and resulting in a high cost of non-production. This model is proposed to optimize the maintenance policy, or the mix of maintenance policies, adopted for wrapping machines for energy cables in the paper that produces batches of different lengths (expressed in $\mathrm{km}$ ). In this model, for each maintenance cycle, each duration coincides with the length of a production batch, $m$ preventive interventions audit, or control are performed; the first $m-1$ are called intermediate controls (CI) while the last is called the pre-start control (C.P.). There is provided with corrective maintenance $(G)$, allowing the system to continue to perform its function in case of failure. Therefore, the maintenance cycle (MC) starts with a system whose reliability tends to $100 \%$ and ending, after $m$ intervals, with a prestart control (C.P.), bringing back again the reliability of the system to a value tending to $100 \%$, after which a new cycle begins maintenance, as shown in Fig. 1.

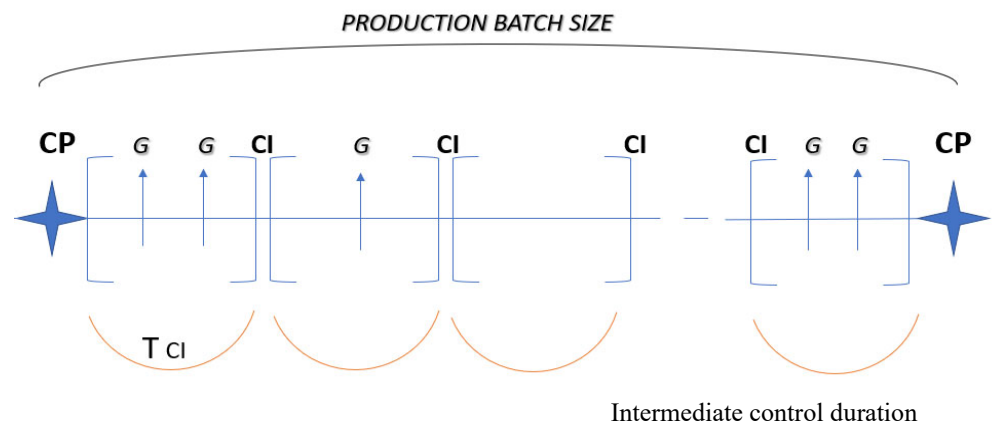

Fig. 1. Evolution of the system with preventive audits

The achievement is to improve the machine's operational availability, i.e., avoid costly failures to reduce the total costs of maintenance. This can be achieved by improving the machine's aggregate reliability, i.e., the propensity for the proper functioning, in the range related to the production of a batch, by a strengthening of preventive controls, whose aim is to improve the reliability.

In the proposed model, the following notation is used as defined in Table 1. 
Table 1. Model Notation

$\boldsymbol{T} \quad$ Mission time (expressed in $\mathrm{km}$ )

$\lambda(t) \quad$ Failure rate of the system depending $\mathrm{t}$

$\boldsymbol{f}(\boldsymbol{t}) \quad$ Density of the probability of system failure depending $\mathrm{t}$

$\boldsymbol{F}(\boldsymbol{t}) \quad$ Unreliability system (cumulative probability of failure) depending $\mathrm{t}$

$\boldsymbol{R}(\boldsymbol{t}) \quad$ System reliability depending $\mathrm{t}$

$\boldsymbol{A}$ Scaling factor of the Weibull distribution or life characteristic of the component (expressed in $\mathrm{km}$ )

$\boldsymbol{B} \quad$ Form factor of the Weibull distribution of the component

$\boldsymbol{T}_{\boldsymbol{L P}} \quad$ Duration of the maintenance cycle (expressed in $\mathrm{km}$ ) or length production batch

$\boldsymbol{T}_{\boldsymbol{C I}} \quad$ Duration of (expressed in $\mathrm{km}$ ) between two intermediate controls or between a intermediate control and a pre-start control

$\boldsymbol{H} \quad$ Number system components

$\boldsymbol{\eta}_{\boldsymbol{C I}} \quad$ Number components changed during an intermediate control (CI) or pre-start control (C.P.)

$\boldsymbol{N}_{\boldsymbol{C I}} \quad$ Number intermediate controls (CI)

$\boldsymbol{N}_{\boldsymbol{M G}} \quad$ Number of stops on a fault in maintenance cycle, (coinciding with the total number of changed components)

C.T. Total cost of maintenance in a maintenance cycle (production batch)

$\boldsymbol{C}_{\boldsymbol{M G}} \quad$ Cost of corrective maintenance (G)

$\boldsymbol{C}_{\boldsymbol{C I}} \quad$ Cost of intermediate maintenance (CI)

$\boldsymbol{C}_{\boldsymbol{C P}} \quad$ Cost of pre-start maintenance (C.P.)

$\boldsymbol{C}_{\boldsymbol{C}} \quad$ Unit cost of the component

$\boldsymbol{T}_{\text {int }} \quad$ Maintenance operation time (it is different in the various types of maintenance, int the C.P. is greater

$\boldsymbol{C}_{\text {working time }}$ Hourly cost worker

$\boldsymbol{N}_{\text {workers }} \quad$ Number of workers used in maintenance operation

$\boldsymbol{C}_{\boldsymbol{o p p}} \quad$ Opportunity cost for lost production in corrective maintenance

$\boldsymbol{C}_{\text {stop }} \quad$ Opportunity cost for lost production in intermediate maintenance and pre-start maintenance

$\boldsymbol{V}_{\text {prod }} \quad$ Speed of the hourly machine production

The proposed model is valid under the following assumptions:

- $\quad$ Reliability features, $\mathrm{R}(\mathrm{t}), \mathrm{F}(\mathrm{t}), \mathrm{f}(\mathrm{t})$ and $\lambda(\mathrm{t})$ of the component, are distributed according to a Weibull distribution like:

$$
R(t)=e^{-\left(\frac{t}{\alpha}\right)^{\beta}}
$$




$$
\begin{aligned}
& F(t)=1-R(t)=1-e^{-\left(\frac{t}{\alpha}\right)^{\beta}} \\
& f(t)=\frac{d F(t)}{d t}=\lambda(t) \cdot R(t)=\frac{\beta}{\alpha}\left(\frac{t}{\alpha}\right)^{\beta-1} \cdot e^{-\left(\frac{t}{\alpha}\right)^{\beta}} \\
& \lambda(t)=\frac{f(t)}{R(t)}=\frac{\beta}{\alpha}\left(\frac{t}{\alpha}\right)^{\beta-1}
\end{aligned}
$$

where

$\beta<1$ if during infant mortality or run;

$\beta=1$ if during the useful life or random failures;

$\beta>1$ if during the usury or aging;

- Before starting to work (or batch) there is a running-in phase that will prevent infant failures, considering only cases in which $\beta \geq 1$.

- The system consists of identical components in series, so if the reliability of the components is described by a Weibull of parameters $\alpha$ and $\beta$, then the reliability of the total system is still described by a Weibull with parameters $\alpha_{\text {tot }}$ and $\beta$.

- The failure rate of the total system, $\lambda_{s}(t)$, is a function of the failure rates of the $n$ components that constitute the system, $\lambda_{i}(t)$ with $i=1,2, \ldots, n$.

- In any corrective maintenance will be changed only one component.

- The cost of production downtime to corrective maintenance (relative to change of a component) is much greater than the cost of the single component changed to an intermediate maintenance

- There is a restriction by the customer on the interval between two maintenance

- Under these assumptions, the model allows us to minimise the following function:

$$
C T=C_{M G} \times N_{M G}+C_{C I} \times N_{C I}+C_{C P}
$$

i.e. the total cost of maintenance on a maintenance cycle of length $\boldsymbol{T}_{\boldsymbol{L} \boldsymbol{P}}$ (length production batch) where

$$
\begin{aligned}
& C_{M G}=\left(T_{\text {int }} \times C_{\text {opp }} \times V_{\text {prod }}\right)+\left(N_{\text {workes }} \times T_{\text {int }} \times C_{\text {workingtime }}\right)+C_{C} \\
& C_{C I}\left(=C_{C P}\right)=\left(n_{C I} \times C_{C}\right)+\left(N_{\text {workers }} \times T_{\text {int }} \times C_{\text {workingtime }}\right)+\left(C_{\text {stop }} \times T_{\text {int }} \times V_{\text {prod }}\right)
\end{aligned}
$$

Minimising the total maintenance coston cycle maintenance of length $\boldsymbol{T}_{\boldsymbol{L} \boldsymbol{P}}$ (length production batch) is actionable by reducing the number of stops for faults, $\boldsymbol{N}_{\boldsymbol{M G}}$. Thus, it increases, in the considered interval (maintenance cycle) $\boldsymbol{T}_{\boldsymbol{L} P}$, the aggregate reliability of the machine/system, which is equal to:

\section{AGGREGATERELIABILITY}

$$
\begin{aligned}
& =\int_{0}^{T_{C I_{(1)}}} R_{\left[C P \leftrightarrow C I_{1}\right]}(t) d t+\int_{T_{C I_{(1)}}}^{T_{C I_{(2)}}} R_{\left[C I_{(1)} \leftrightarrow C I_{(2)}\right]}(t) d t+\cdots \\
& +\int_{T_{C I_{(i-1)}}}^{T_{C I_{(i)}}} R_{\left[C I_{(i-1)} \leftrightarrow C I_{(i)}\right](t) d t}+\cdots+\int_{T_{C I_{(i-1)}}}^{T_{L P}} R_{\left[C I_{\left(N_{C I}\right)} \leftrightarrow C P\right]}(t) d t
\end{aligned}
$$

- In graphical terms, the system/machine's aggregated reliability is the sum of the areas under the curves of reliability of the system between two maintenance checks ( $\mathrm{CP} \leftrightarrow \mathrm{CI}, \mathrm{CI} \leftrightarrow \mathrm{CI}, \mathrm{CI} \leftrightarrow \mathrm{CP})$. Basically, it is consistent to believe that increasing the system/machine's aggregated reliability increases its operational availability and thus decreases the probability of failure of the components that constitute 
it. In the case of an intermediate control at a $\boldsymbol{T}_{\boldsymbol{C L}}=\mathbf{1 0} \mathbf{~ k m}$, the interruptions or intermediate controls are established according to the formula:

$$
N_{C I}=\frac{T_{L P}}{10}=\frac{k m s i z e}{10} .
$$

rounded to the nearest integer. Then the instant (Expressed in kilometers) in which to make the intermediate controls shall be calculated by the following mathematical problem formulation:

\section{Initialisation}

If $\boldsymbol{T}_{L P} \geq 10$ and $\boldsymbol{T}_{L P}-10<10$

then $T_{C I}=\frac{T_{L P}}{2}$

else $\boldsymbol{T}_{C I}=10$

end.

Generalising, for the number of intermediate, $N_{C I}$ :

Set $\boldsymbol{T}_{C I_{(i=0)}}$;

For $i=1,2, \ldots, N_{C I}$

$\boldsymbol{I f}\left(\boldsymbol{T}_{\boldsymbol{L P}}-\boldsymbol{T}_{\boldsymbol{C I}_{(1)}}\right)-10 \geq 10$

then $\boldsymbol{T}_{C I_{(i+1)}}=\boldsymbol{T}_{C I_{(i)}}+10$

else $T_{C I_{(i+1)}}=T_{C I_{(i)}}+\frac{T_{L P}-T_{C I_{(i)}}}{2}$

Then, in correspondence of the i-th time $\boldsymbol{T}_{\boldsymbol{C I}(t)}($ expressed in $\mathrm{km})$ in which will be performed intermediate control, known the reliability function of the total system, will be calculated the number of components to be changed $\boldsymbol{n}_{\boldsymbol{C I}(\boldsymbol{t})}$, by the following equation:

$$
n_{C I(t)}=\left[1-R\left(T_{C I(t)}\right)\right] \times n
$$

where:

$\boldsymbol{R}\left(\boldsymbol{T}_{\boldsymbol{C I}(t)}\right)=$ System reliability to i-th maintenance check

$1-\boldsymbol{R}\left(\boldsymbol{T}_{\boldsymbol{C I}(\boldsymbol{t})}\right)=$ Systemunreliabilitytoi-th maintenance check

Therefore, after the intermediate control, the total system is reported at a level of reliability more excellent to increase its operational availability. Starting the new maintenance cycle from time TCI (t) with a new reliability function calculated as the product of the components' reliability curves that compose it. The considered reliability curves of each component take into account that starting from the time i-th, some components have never been changed from the start cycle. Instead, some components have been changed to the time i-land other components changed to the time $i$. Therefore, the considered Weibull model will always have the same size but are considered from different times. In conclusion, for this considered production system, the optimum maintenance policy, which improves the total system aggregate reliability, involves a greater operating availability, i.e., a reduction in the number of stops for failure and then a decreasing total cost.

\section{Case study}

\subsection{Identification of critical components and data collection}

The first step is data collection to identify problems affecting the wrapping machine. In particular mechanical failures, the fault data were collected for the three types of maintenance: pre-start control, 
intermediate control, and corrective maintenance. These data contain information about the most common problems, i.e., for each machine stop, were highlighted the causes and the related operations performed to restore the correct machine working condition. Data collection lasted 50 days where a cable of about 24375 meters (about $24 \mathrm{~km}$ ) was realized. Table 2 shows the number of maintenance operations for the three types of maintenance (Corrective maintenance, Pre-start Control, Intermediate Control).

Table 2. Number of maintenance operations for the three types of maintenance on a wrapping line

\begin{tabular}{cccc}
\hline & \multicolumn{2}{c}{ MACHINE } \\
\hline OPERATION & $\begin{array}{c}\text { CORRECTIVE } \\
\text { MAINTENANCE }\end{array}$ & INTERMEDIATE CONTROL & PRE-START CONTROL \\
\hline Operation 1 & 3 & 24 & 18 \\
Operation 2 & 4 & 7 & 0 \\
Operation 3 & 4 & 24 & 27 \\
Operation 4 & 3 & 2 & 0 \\
Operation 5 & 0 & 0 & 9 \\
Operation 6 & 1 & 0 & 0 \\
Operation 7 & 9 & 57 & 90 \\
Operation 8 & 2 & 0 & 2 \\
Operation 9 & 0 & 1 & 1 \\
Operation 10 & 0 & 1 & 0 \\
Operation 11 & 18 & 70 & 150 \\
Operation 12 & 2 & 2 & 10 \\
\hline TOT. MAINTENANCE & 46 & 188 & 307 \\
\hline
\end{tabular}

The purpose of collecting data is to identify the C.C, i.e., which components have a higher weight, above all, about the machine wrapper's reliability and availability. Table 3 shows each type of maintenance (Corrective maintenance, Intermediate Control).

Table 3. Number of corrective maintenance operations

\begin{tabular}{ccc} 
& MACHINE & \\
& CORRECTIVE MAINTENANCE & \% OPERATIONS \\
\hline COMPONENT & MACHINE & $51.1 \%$ \\
\hline Component 1 & 22 & $30.2 \%$ \\
Component 2 & 13 & $7.0 \%$ \\
Component 3 & 3 & $4.7 \%$ \\
Component 4 & 2 & $4.7 \%$ \\
Component 5 & 2 & $2.3 \%$ \\
\hline Component 6 & 1 & \\
\hline TOTAL & $\mathbf{4 3}$ & \\
\hline
\end{tabular}

In conclusion, it was identified the c.c. of the machine, i.e., because the C.C., on it the most of maintenance operations, were concentrated, both of which were corrective maintenance that those of scheduled maintenance. It was shown that even though it carried out the intermediate control, at half cable length, at about $12 \mathrm{~km}$, and where at the operation eleven, 70 components were changed. Therefore, the machine stopped 18 times for the same problem. It was also shown that the cost of production downtime for corrective maintenance on the replacement of a disk is much higher than the cost of the single component replaced in intermediate maintenance.

\subsection{Maintenance operation on critical machine}

The attention was focused on a single machine in the maintenance process, the wrapping machine for energy cables in the paper. This one was considered, by the management, critical for the production process, due to continuous stops on a fault. A wrapping machine is a machine composed of 20 heads, and each head is composed of 12 identical brackets. A bracket is constituted by a beam of light alloy on which is mounted the braking disk or disk carries rolls of paper. On the disk's drum, it is fixed the friction lining (lining), on which the steel strip (strip). 


\subsection{Maintenance wrapping machine}

In the analyzed manufacturing plant, the standard policy of periodic maintenance is not applied. Instead, a particular type of periodic maintenance called maintenance review or complete inspection and repair is developed. It is usually carried out by disassembling and inspecting the whole plant/machine periodically to repair or change only the damaged or worn parts. To ensure the proper functioning of the wrapping machine during each batch's production, i.e., during the wrapping of a specific size of the produced cable, three types of maintenance are represented in Fig. 1 are needed:

1. Pre-start Control (C.P.);

2. Intermediate Control (CI)

3. Corrective maintenance $(\mathrm{G})$.

\subsubsection{Pre-start Control}

Before starting the cable's wrapping or right at the beginning of each batch, the Pre-start Control is carried out. It consists of an extensive control whose purpose is to ensure the proper machine operating in terms of reliability. This control has the purpose of bringing the machine to a level of reliability, which tends to the state of "as good as new," bringing the failure rate to its initial value.

\subsubsection{Intermediate Control}

The Intermediate Control on customer requirements is carried out not over $10 \mathrm{~km}$ of cable wrapped, in order to obtain an increased product quality. In terms of reliability, this control does not bring the machine to the $100 \%$ reliability as in the pre-start control; it guarantees a level of acceptable reliability to produce a high-quality cable. Furthermore, unlike the pre-start control, the intermediate control is carried out with "the cable in the machine." Therefore, the maintenance operations which are necessary to restore the correct machine's state must be carried out not to damage the cable. This control is carried out by stopping the production for enough time to control all the wrapping machine heads.

\subsubsection{Corrective maintenance}

Corrective maintenance is needed when a fault occurs in the machine during the cable wrapping. When the components which have determined the fault are identified, it proceeds to repair through a mechanical operation of cleaning, adjusting, and/or replacement.

\section{Literature review}

Many authors have dealt with the maintenance field during their studies (such as Riquero et al., (2019)) in which he declares the quick changes lead the organizations in business demand toward higher efficacy and efficiency on all sides. Subsequently, in their research, Edwards and Love (2015) have established that the fundamental requirement for safe and productive operations on-site is proper scheduled and daily maintenance of machinery and infrastructure. Consequently, it has been considered essential to follow a model composed of maintenance procedures and protocols that can be implemented in all systems of the organization. The performance of TPM development has been dealt with by Shen (2015), providing details of execution, planning, and methodology with the work team, management and operators. This will allow the improvement of both equipment and operations by means of failure reductions.

The result has been obtained to lead to 12-steps TPM implementation and a process that can take 35 years to implement. From this result, Amad et al., (2011) agree that developing autonomous 
maintenance (M.A.) increases and practices the reliability and availability of machinery. The key is to follow up the process on top of the planned maintenance. Prabhaka et al., (2013) in their research work, deals with the maintenance model based both on predictive maintenance (PDM) and preventive maintenance $(\mathrm{PM})$ that gets integrated with the initial processes of reliability-centered maintenance (RCM). Sillivant (2015) mainly focused on improving industrial machine maintenance intervention times to maximize production and, consequently, the profit. Maintenance interventions should be performed quickly with standardized procedures, but this is not always possible because of the complexity of the various production systems and the vast number of components that it presents.

In most cases, it takes a long time to get proper maintenance. The analysis carried out by Tee and Ekpiwhre (2019) show how maintenance is a set of actions that should be performed by qualified operators ready to solve the problems that occur by minimizing waste, downtime, and recovering undamaged components in order to ensure high efficiency of systems and components. Rimawan and Bambang (2017) claim that to maintain high reliability and total productivity, it is necessary to perform ordinary maintenance, assigning the degree of efficiency to the various components. Furthermore, it is necessary to monitor each machine's operations to measure its effectiveness and reliability in each production cycle. An important aspect is represented by the skill level of specialized operators; in fact, Holt and Edwards (2015) highlighted that a critical element of operational productivity is the operator's ability, faced with the need to act quickly, to maintain high and reliable machinery operations. Finally, Chen et al., (2016) developed a model for the study of degradation by individually monitoring the production systems and obtained excellent results. It is necessary to analyze a wide number of data that is obtained through sensors. Thanks to this study, they have also noticed an opportune analysis on the degradation times based on the usage of machinery.

\section{Implementation of the model}

The model was implemented through the reliability theory. When the C.C. is found, a study of the component reliability is conducted to get on the machine wrapper's functional reliability. Among the different models of reliability, it was decided to study the reliability using the Weibull distribution because it allows modeling all stages of the life cycle of an entity by changing the values of the characteristic parameters of the distribution, i.e., the value of the scale parameter $\alpha$ and the value of the parameter $\beta$. In order to derive the reliability function from the method of Weibull, it is necessary to know the values of the distribution's characteristic parameters. In order to evaluate these values, a sample of 18 components. The estimation of the parameters $\alpha$ and $\beta$, having ordered the fault data ascending, was performed using before the maximum likelihood method and then the graph method of Weibull's Probability Plot, using the linear regression method. The procedure followed was implemented in MATLAB.

\subsection{MATLAB CODE 1}

It follows that the values of the parameters $\alpha$ and $\beta$, which define the Weibull distribution, which is used to describe the reliability of the component to failure are: $\alpha=65, \beta=3.5 \mathrm{~km}$.

Note the values of the parameters $\alpha$ and $\beta$ can be derived from the trend of the reliability $R(t)$ and of the other features of reliability, $\lambda(t), f(t), F(t)$ of the component under consideration. Fig. 2 shows the trend of the reliability functions, i.e., $\mathrm{f}(\mathrm{t}), \mathrm{F}(\mathrm{t}), \mathrm{R}(\mathrm{t})$.

\subsection{MATLAB CODE 2}

Derived the single component's reliability function can be derived from the machine object of study, i.e., wrapping machine since it is a system whose components are arranged in series, the failure even of a single c.c. leads to a failure of the whole machine; therefore, the reliability is: 


$$
R_{S}(t)=R_{1}(t) \cdot R_{2}(t) \cdot \ldots \cdot R_{n}(t)=\prod_{i=1}^{n} R_{i}(t)
$$

i.e., the system reliability at time $t$ is the product of all the components' reliability at time $t$. In the case of a system constituted by $n$ identical components in series, whose reliability is described by a Weibull of parameters $\alpha$ and $\beta$, then the reliability of the overall system is still described by a Weibull of parameters:

$$
\beta \text { e } \alpha_{t o t}=\frac{\alpha}{n^{\frac{1}{\beta}}}
$$

Therefore, the reliability of the overall system is:
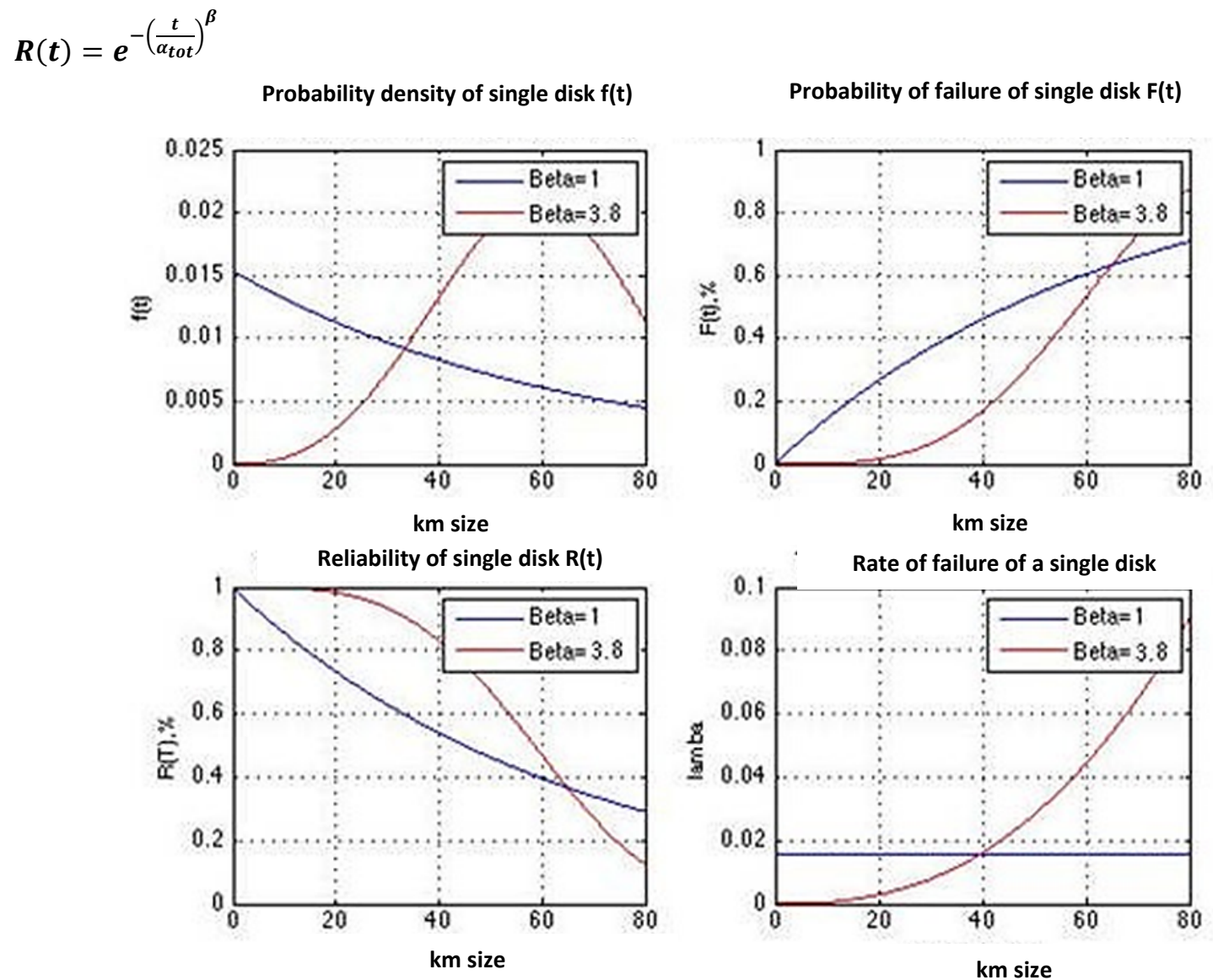

Fig. 2. Trends of $f(t), \lambda(t), F(t), R(t)$ tor the braking disk

Note the values of the parameters $\alpha_{t o t}$, and $\beta$ has derived the trend of the reliability $R(t)$ and of the other features of reliability, $\lambda(t), f(t), F(t)$, and then, the behavior of the machine to fail. Below is the code implemented in MATLAB to derive the trend of $\mathrm{f}(\mathrm{t})$ and $\mathrm{F}(\mathrm{t})$ (Fig. 3).

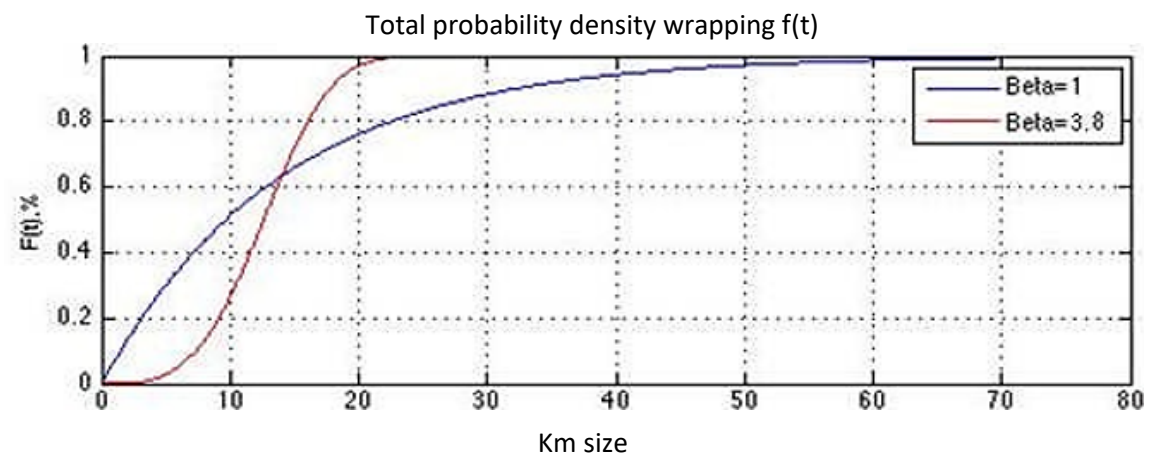




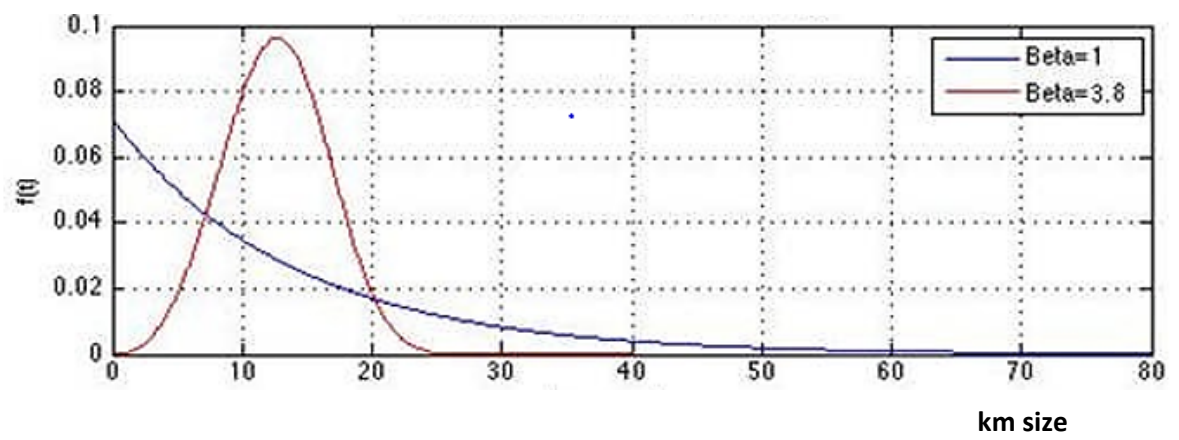

Fig. 3. Trend of $f(t), \lambda(t), F(t), R(t)$ for the braking disk

\subsection{MATLAB CODE 3}

Below is the code implemented in MATLAB to derive the trends of reliability $\mathrm{R}(\mathrm{t})$ of the machine wrapping machine, in maintenance context examined, i.e., for a batch of $24 \mathrm{~km}$ of cable, and to determine the area under curves of reliability, which we remember is the aggregate reliability, i.e., the propensity of a machine to proper operation in the range considered (Fig. 4).
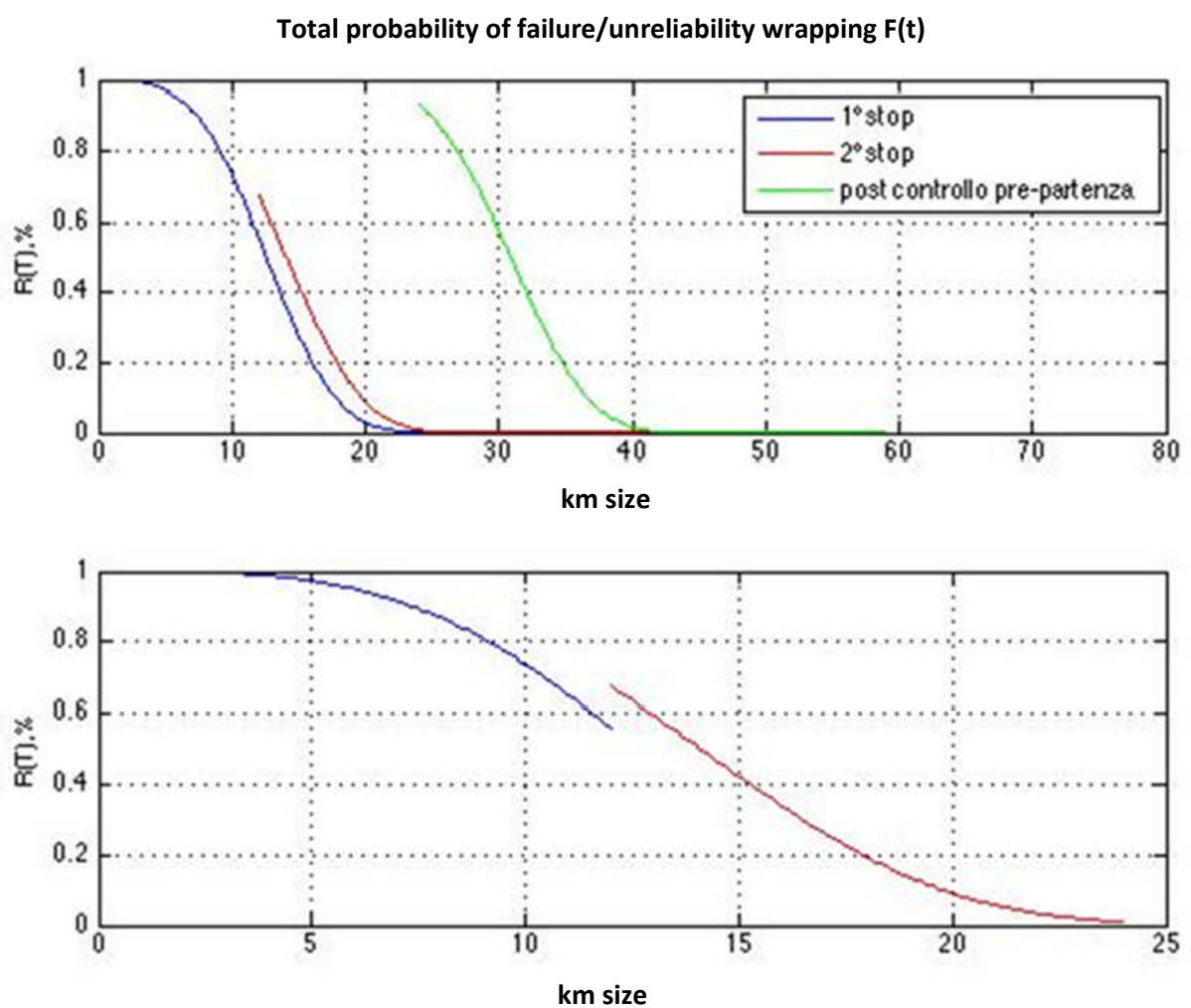

Fig. 4. Current maintenance policy for the wrapping machine SACOI

\subsection{MATLAB CODE 4}

This context (Fig. 5), which represents the current maintenance policy adopted, was carried out. Only one intermediate control was done, at $12 \mathrm{~km}$, (i.e., in the middle batch), when the machine had the reliability of $\approx 55 \%$. In this control point, 70 disks were changed, and the machine reliability goes back to a value of $\approx 65 \%$. A pre-start control was done at $24 \mathrm{~km}$ (i.e., for the next batch), when the machine reliability was less than 10\%: 150 disks were changed, bringing back the machine's reliability to a value of $\approx 100 \%$. Then it was calculated the aggregate reliability of the machine in the operating range $(0-24$ 
$\mathrm{km}$ ) simply by adding up the area underlying the two curves of reliability, getting $13,65 \mathrm{~km}$. Then it was decided to implement the proposed model to define a new maintenance policy to be adopted, referring to a batch of the same type. The proposed model is used to define the number of intermediate controls needed and the instant in which to carry out control, in observance of the constraint imposed by a customer: at least every $10 \mathrm{~km}$ of cable wrapped. It also allows calculating the number of C.C. to be replaced, during these controls, in order to restore a higher reliability machine. Since the batch is $24 \mathrm{~km}$, it is found that the intermediate controls to be made are 2 :

$$
N_{C I}=\frac{T_{L P}}{10}=\frac{k m s i z e}{10}=\frac{24 \mathrm{~km}}{10}=2.4 \approx 2
$$

Moreover, using the algorithm, we calculate the time (in $\mathrm{km}$ ) in which to make such intermediate controls:

$$
\begin{gathered}
24-10=14 \geq 10 \rightarrow \boldsymbol{T}_{\boldsymbol{C I}(1)}=\boldsymbol{T} 1=10 \\
(24-10)-10=4 \leq 10 \rightarrow \boldsymbol{T}_{\boldsymbol{C I}(2)}=\boldsymbol{T} 2=10+\frac{14}{2}=10+7=17
\end{gathered}
$$

i.e., one to $10 \mathrm{~km}$ and the other at $17 \mathrm{~km}$. Moreover, it is considered the last check, the pre-start control (for the next batch) carried out at $24 \mathrm{~km}$, as in the current maintenance policy. Below is visible the code implemented in MATLAB to derive the trends of the reliability $R(t)$ of the machine wrapper in the new maintenance context and the aggregate reliability, i.e., the propensity of a machine to the first operation in the range considered.
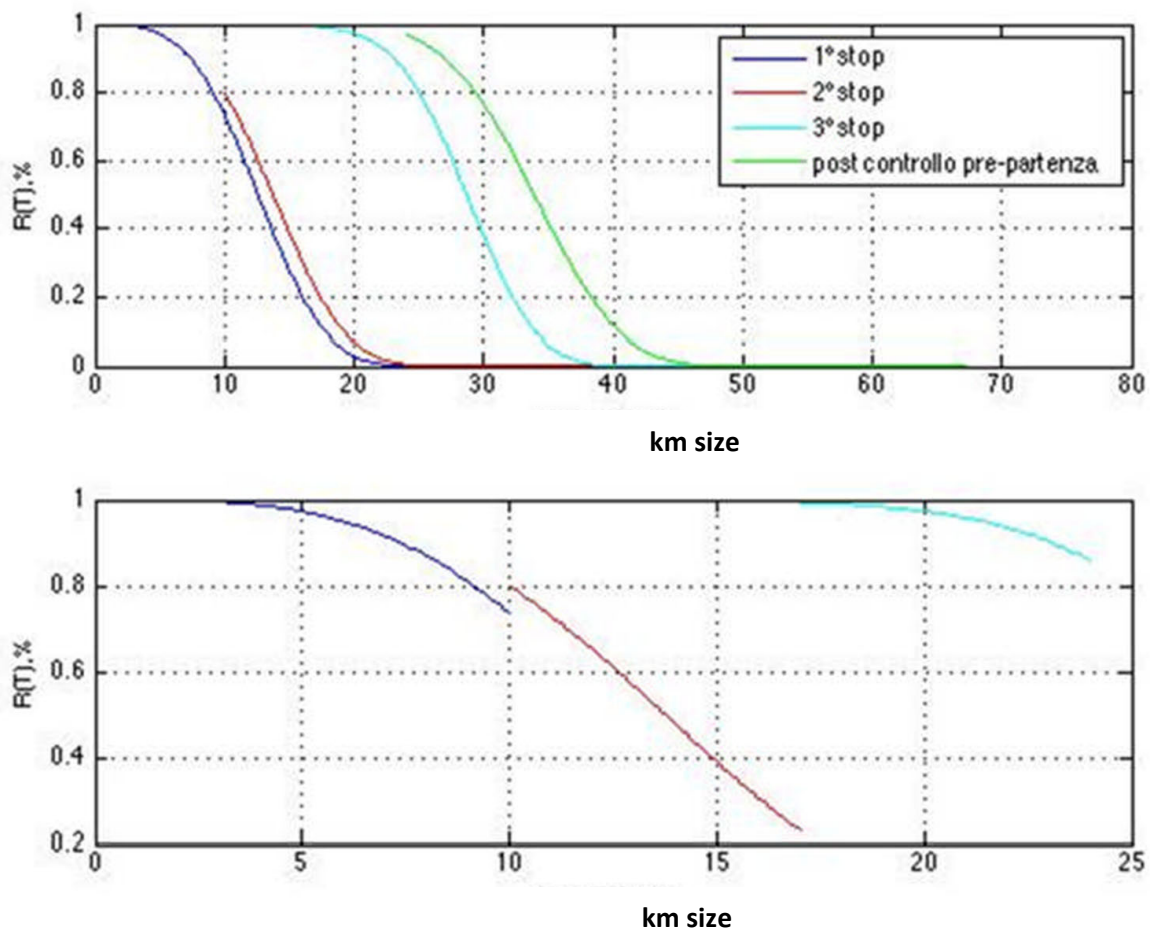

Fig. 5. Maintenance policy proposed for the wrapping machine

It is noted that at the first control carried out at $10 \mathrm{~km}$, the machine has a reliability of $\approx 75 \%$, in that control, the model proposes to change 55 disks, to bring back the reliability of the machine to a value of $\approx 80 \%$; while at the second control, carried out at $17 \mathrm{~km}$, the machine has a reliability of $\approx 23 \%$, in that control the model proposes to change 175 c.c., to bring back the reliability of the machine to a value close to $100 \%$. Finally, in the last control, i.e., the pre-start control (for the next batch) carried out, then, at $24 \mathrm{~km}$, the machine turns out to have a reliability of $\approx 75 \%$, in that control, the model proposed to 
change 55 c.c., to bring back the reliability of the machine to a value close to $100 \%$. Then it was calculated the aggregate reliability of the machine in the operating range $(0-24 \mathrm{~km})$ only by adding up the area underlying the two curves of reliability, getting $19.27 \mathrm{~km}$.

\section{Result and analysis}

By comparing the machine's aggregated reliability in the operating range $(0-24 \mathrm{~km})$ calculated for the two maintenance contexts, the current one and the one obtained by implementing the proposed model showed an improvement of $41 \%$. Analytically it is given by:

$$
\frac{19,42-13,65}{13.65}=0,41=41 \%
$$

So an improvement of the machine's reliability aggregate is translated into an improvement of the availability of the machine and therefore in a reduction of corrective maintenance, and therefore, in this case, in a lower number of C.C. it replaced to failure or a reduction of machine downtime or production downtime. Recalling that the number of operations of corrective maintenance on the C.C. was 18, it follows that an improvement of $41 \%$ of aggregate reliability involves having about eight stops. Corrective maintenance cost is certainly much greater than the cost of a single C.C. replaced in the operation of preventive control, leading to a lower total cost of maintenance. This was demonstrated by assessing the relative cost for both policies, using the following relationship:

$$
C T=C_{M G} \times N_{M G}+C_{C I} \times N_{C I}+C_{C P}
$$

where

$$
\begin{aligned}
C_{M G} & =\left(T_{\text {int }} \times C_{\text {opp }} \times V_{\text {prod }}\right)+\left(N_{\text {workers }} \times T_{\text {int }} \times C_{\text {working time }}\right)+C_{C} \\
C_{C I}\left(=C_{C P}\right) & =\left(n_{C I} * C_{C}\right)+\left(N_{\text {workers }} \times T_{\text {int }} \times C_{\text {working time }}\right)+\left(C_{\text {stop }} \times T_{\text {int }} \times V_{\text {prod }}\right)
\end{aligned}
$$

\begin{tabular}{|c|c|}
\hline Intermediate Control & $N_{C I}=1$ \\
\hline Pre-start Control & $N_{C P}=1$ \\
\hline Total number of c.c. replaced in corrective maintenance & $N_{M G}=18$ \\
\hline Total number of c.c. replaced in intermediate control & $\boldsymbol{n}_{C I}=70$ \\
\hline Total number of c.c. replaced in pre-start control & $n_{C I}=150$ \\
\hline Maintenance operation time in corrective maintenance & $T_{\text {int }}=1 \mathrm{~h}$ \\
\hline Maintenance operation time in intermediate control and pre-start control & $T_{\text {int }}=5$ days \\
\hline Machine speed & $V_{\text {prod }}=3,1 \frac{\boldsymbol{m}}{\boldsymbol{m i n}}$ \\
\hline Hourly cost worker & $C_{\text {working time }}=\frac{15 €}{h}$ \\
\hline $\begin{array}{l}\text { Opportunity cost for lost production in corrective maintenance (multiplied by } 0.07 \text { to } \\
\text { account for saturation levels) }\end{array}$ & $C_{\text {opp }}=50 €$ \\
\hline Opportunity cost for lost production in intermediate control and pre-start control & $C_{\text {stop }}=1 €$ \\
\hline Number of workers used in corrective maintenance & $N_{\text {workers }}=1$ \\
\hline Number of workers used in intermediate control and pre-start control & $N_{\text {workers }}=3$ \\
\hline Cost c.c. & $C_{c}=150$ \\
\hline
\end{tabular}

It is highlighted that the cost and time, used in the implementation of the model, are estimates, partly given by those responsible for maintenance and partly by making inquiries, (see Tables 4 and 5).

Table 5. Maintenance context current

\begin{tabular}{|c|c|}
\hline Intermediate Control & $N_{C I}=2$ \\
\hline Pre-start Control & $N_{C P}=1$ \\
\hline Total number of c.c. replaced in corrective maintenance & $N_{M G}=10$ \\
\hline Total number of c.c. replaced in the $1^{\text {st }}$ intermediate control & $\boldsymbol{n}_{C I}=20$ \\
\hline Total number of c.c. replaced in the $2^{\text {nd }}$ intermediate control & $n_{C I}=167$ \\
\hline Total number of c.c. replaced in pre-start control & $\boldsymbol{n}_{C I}=55$ \\
\hline
\end{tabular}

So, the total cost of maintenance for the current context is $€ 261810$.

Table 5. Maintenance context derived from the proposed model. 
Time and cost and other parameters are the same in the current maintenance context. So, the total cost of maintenance for this new context is $€ 214.210$.

\section{Conclusions}

Nowadays, manufacturers have to consider some important factors to reach their goals economically and productively, such as the competition, the loss of economic capital, and the technological explosion. These are leading to an increasingly rapid change in production processes. The company should focus their attention on the life cycles of products that are always becoming shorter and shorter. Thanks to intellectual minds and the new evolutive engineering advantages involved in increasingly reliable production processes, these companies and their activities become increasingly prosperous. A company is based on the effective implementation of its physical resources, which people and processes. It is still important to pay attention to the effective management of the costs in relation to the capacities that the company may give. The real potential consists of the minimization of the waste of a company's resources, but this minimization starts from the improvement proposals that involve the optimization of the resources in all levels of the company. The improvement is obtained by means of a series of action-based tools to allow the creation of products and services to customers in a way better, faster and cheaper. A mathematical model has been implemented. The point of starting is the optimization of the maintenance policies to reach the set target of continuous improvement of the machine and containment's operational availability and containment, ensuring the maximal efficiency and lower costs. However, maintenance should not be seen as a cost because appropriate continuous maintenance allows getting cost savings in the long term. The proposed model uses mainly the theory of reliability. As a matter of fact, an aggregate reliability machine improvement influences the availability of the machine reducing maintenance operations to be carried out. Thus, the obtained results show that the proposed model optimizes the current preventive and cyclical maintenance policy, with a reduction in failure interventions that correspond to a reduction of the total cost of maintenance.

\section{References}

Cárcel-Carrasco, J., Cárcel-Carrasco, J. A., \& Peñalvo-López, E. (2020). Factors in the relationship between maintenance engineering and knowledge management. Applied Sciences, 10(8), 2810.

Carnero, M. C., \& Gómez, A. (2016). A multicriteria decision making approach applied to improving maintenance policies in healthcare organizations. BMC Medical Informatics and Decision Making, 16(1), 1-22.

Chemweno, P., Pintelon, L., Van Horenbeek, A., \& Muchiri, P. (2015). Development of a risk assessment selection methodology for asset maintenance decision making: An analytic network process (ANP) approach. International Journal of Production Economics, 170, 663-676.

Cheng, Q., Wang, S., \& Yan, C. (2016). Robust optimal design of chilled water systems in buildings with quantified uncertainty and reliability for minimized life-cycle cost. Energy and Buildings, 126, 159169.

Ciarapica, F. E., Giacchetta, G., \& Paciarotti, C. (2008). Facility management in the healthcare sector: analysis of the Italian situation. Production Planning \& Control, 19(4), 327-341.

de Jonge, B., \& Scarf, P. A. (2020). A review on maintenance optimization. European journal of operational research, 285(3), 805-824.

Deepak Prabhakar, P., \& VP, D. J. R. (2013). A new model for reliability centered maintenance in petroleum refineries. International Journal of Scientific \& Technology Research, 2(5).

Edwards, D. J., \& Love, P. E. (2016). A case study of machinery maintenance protocols and procedures within the UK utilities sector. Accident Analysis \& Prevention, 93, 319-329.

Exner, K., Schnürmacher, C., Adolphy, S., \& Stark, R. (2017). Proactive maintenance as success factor for use-oriented Product-Service Systems. Procedia CIRP, 64, 330-335.

Furlanetto, L., Garetti, M., \& Macchi, M. (2007). Ingegneria della manutenzione. Strategie e metodi. Milano: Franco Angeli. 
Geisler, E. (2002). Trends in Hospital and Healthcare Technologies-The future. Hospital Engineering and Facilities Management, 18-22.

Holt, G. D., \& Edwards, D. (2015). Analysis of interrelationships among excavator productivity modifying factors. International Journal of Productivity and Performance Management.

Irhirane, E., Bounit, A., Dakkak, B., Benmoussa, R., \& Bourquia, N. (2019). New approach integrating the health, safety, and environment systems for the maintenance function in industries. Proceedings of the Institution of Mechanical Engineers, Part E: Journal of Process Mechanical Engineering, 233(4), 926-941.

Jardine, A. K., \& Tsang, A. H. (2005). Maintenance, replacement, and reliability: theory and applications. CRC press.

Lidén, T. (2015). Railway infrastructure maintenance-a survey of planning problems and conducted research. Transportation Research Procedia, 10, 574-583.

Lidén, T. (2016). Towards concurrent planning of railway maintenance and train services (Vol. 1746). Linköping University Electronic Press.

Marchi, B., Zanoni, S., Mazzoldi, L., \& Reboldi, R. (2016). Product-service system for sustainable EAF transformers: real operation conditions and maintenance impacts on the life-cycle cost. Procedia CIRP, 47, 72-77.

Min, C. S., Ahmad, R., Kamaruddin, S., \& Azid, I. A. (2011). Development of autonomous maintenance implementation framework for semiconductor industries. International Journal of Industrial and Systems Engineering, 9(3), 268-297.

RAMS) (pp. 1-5). IEEE.

Rimawan, E., Irawan, A. P. B., \& Priyo, B. (2017). Analysis of Calculation Overall Equipment Effectiveness (OEE) in the Implementation of Total Productive Maintenance (TPM) PC 200-8 Excavator Grab and Magnet Type Case Study in Cakratunggal Steel Mills Company. International Journal of Scientific \& Engineering Research, 8(1), 1363-1368.

Riquero, I., Hilario, C., Chavez, P., \& Raymundo, C. (2018, October). Improvement proposal for the logistics process of importing SMEs in Peru through lean, inventories, and change management. In Brazilian Technology Symposium (pp. 495-501). Springer, Cham.

Shen, C. C. (2015). Discussion on key successful factors of TPM in enterprises. Journal of applied research and technology, 13(3), 425-427.

Sillivant, D. (2015, January). Reliability centered maintenance cost modeling: Lost opportunity cost. In 2015 Annual Reliability and Maintainability Symposium (

Tee, K. F., \& Ekpiwhre, E. (2019). Reliability-based preventive maintenance strategies of road junction systems. International Journal of Quality \& Reliability Management.

Vaurio, J. K. (1995). Optimization of test and maintenance intervals based on risk and cost. Reliability Engineering \& System Safety, 49(1), 23-36.

Vineyard, M., Amoako-Gyampah, K., \& Meredith, J. R. (2000). An evaluation of maintenance policies for flexible manufacturing systems: a case study. International Journal of Operations \& Production Management.

Zequeira, R. I., \& Bérenguer, C. (2005). Optimal inspection policies with predictive and preventive maintenance. Engineering Optimization, 37(5), 541-550.

Zhang, A., Zhang, T., Barros, A., \& Liu, Y. (2020). Optimization of maintenances following proof tests for the final element of a safety-instrumented system. Reliability Engineering \& System Safety, 196, 106779.

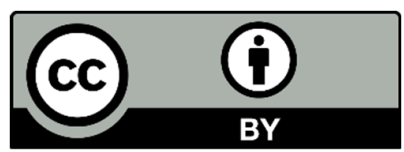

(C) 2021 by the authors; licensee Growing Science, Canada. This is an open access article distributed under the terms and conditions of the Creative Commons Attribution (CC-BY) license (http://creativecommons.org/licenses/by/4.0/). 